\title{
ANÁLISE INTEGRATIVA DAS PRINCIPAIS ZOONOSES DE OCORRÊNCIA NO BRASIL
}

\author{
INTEGRATIVE ANALYSIS OF THE MAIN ZOONOSIS OF \\ OCCURRENCE IN BRAZIL
}

\author{
INTEGRATIVE ANALYSIS OF THE MAIN ZOONOSIS OF \\ OCCURRENCE IN BRAZIL
}

\author{
Gilberto Cezar Pavanelli* \\ pavanelli@nupelia.uem.br \\ Ana Carolina Soares Avelar** \\ ana_carolinavelar@hotmail.com \\ Caroline Côrtes Donida** \\ carolinedonida@gmail.com
}

Weber Alexandre Sobreira Moraes* weberalexandre@me.com

Lucas França Garcia* lucasfgarcia@gmail.com

\footnotetext{
* Programa de Pós-Graduação em Promoção da Saúde, UniCesumar
} ** Curso de Medicina, UniCesumar

\begin{abstract}
Resumo
As zoonoses são doenças ou infecções naturalmente transmissíveis entre animais vertebrados e seres humanos. Os agentes responsáveis por desencadear essas enfermidades podem ser os vírus, bactérias, fungos, parasitos e rickettsias. A transmissão pode ocorrer de forma direta onde há contato com secreções que contém os patógenos, ou indireta, que exige contato físico do ser humano com o animal vetor. A maioria das zoonoses é conhecida como doenças negligenciadas e caracterizam um grupo de doenças tropicais endêmicas, que ocorrem em países subdesenvolvidos e em desenvolvimento, geralmente associadas a pobreza. Ao todo, as zoonoses causam entre 500 mil e 1 milhão de óbitos anualmente, o que expressa a gravidade das mesmas. A fim de ter um controle sobre as zoonoses, é necessário a detecção precoce e a notificação dessas doenças aos órgãos públicos, bem como o compartilhamento de informações seguras entre países. Dessa forma, a prevenção, vigilância, biossegurança, controle de infecção e tratamento de doenças infecciosas são imprescindíveis para que se possa desenvolver um trabalho multidisciplinar de contingência para as zoonoses. Tendo em vista esse cenário, a presente pesquisa, realiza uma análise integrativa das zoonoses humanas que afetam o Brasil, no qual se busca identificar as zoonoses mais prevalentes e as caraterísticas que prédispõe o Brasil a manifestar tais zoonoses. Espera-se que os resultados encontrados possam contribuir principalmente para os programas preventivos das zoonoses que afetam o país, bem como instruir a população sobre a necessidade de medidas preventivas para a diminuição de casos e eventualmente erradicação de algumas delas.
\end{abstract}

Palavras Chave: Doenças negligenciadas. Epidemiologia. Medidas preventivas. País subdesenvolvido.

\begin{abstract}
Zoonosis are diseases or infections that are naturally transmissible between vertebrate animals and humans. The agents responsible for triggering these diseases may be virus, bacteria, fungi, parasites and rickettsiae. Transmission can occur directly where there is contact with secretions containing the pathogens, or indirectly, which requires physical contact between humans and the vector animal. Most zoonoses are known as neglected diseases and characterize a group of endemic tropical diseases that occur in underdeveloped and developing countries, often associated with poverty. In all, zoonoses cause between 500,000 and 1 million deaths annually, which expresses their severity. In order to have control over zoonoses, early detection and notification of these diseases to public agencies is required, as well as the sharing of secure information between countries. Thus, prevention, surveillance, biosecurity, infection control and treatment of
\end{abstract}


infectious diseases are essential for the development of multidisciplinary contingency work for zoonoses. In view of this scenario, the present research performs an integrative analysis of human zoonoses that affect Brazil, which seeks to identify the most prevalent zoonoses and the characteristics that Brazil pre-disposes to manifest such zoonoses. It is hoped that the results found may contribute mainly to the preventive programs of zoonoses that affect the country, as well as educate the population on the need for preventive measures to reduce cases and eventually eradicate some of them.

Keywords: Brazil. Neglected diseases. Epidemiology. Preventive measures. Underdeveloped country.

\begin{abstract}
Resumen
Las zoonosis son enfermedades o infecciones que se transmiten naturalmente entre los animales vertebrados y los humanos. Los agentes responsables de desencadenar estas enfermedades pueden ser virus, bacterias, hongos, parásitos y rickettsias. La transmisión puede ocurrir directamente donde hay contacto con secreciones que contienen los patógenos, o indirectamente, lo que requiere contacto físico entre los humanos y el animal vector. La mayoría de las zoonosis se conocen como enfermedades olvidadas y caracterizan a un grupo e enfermedades tropicales endémicas que ocurren en países subdesarrollados y en desarrollo, a menudo asociados con la pobreza. En total, las zoonosis causan entre 500,000 y 1 millón de muertes al año, lo que expresa su gravedad. Para tener control sobre las zoonosis, se requiere la detección temprana y la notificación de estas enfermedades a las agencias públicas, así como el intercambio de información segura entre países. Por lo tanto, la prevención, la vigilancia, la bioseguridad, el control de infecciones y el tratamiento de enfermedades infecciosas son esenciales para el desarrollo del trabajo de contingencia multidisciplinario para las zoonosis. Dado este escenario, la presente investigación lleva a cabo un análisis integrador de las zoonosis humanas que afectan a Brasil, que busca identificar las zoonosis más prevalentes y las características que Brasil predispone a manifestar tales zoonosis. Se espera que los resultados encontrados puedan contribuir principalmente a los programas preventivos de zoonosis que afectan al país, así como educar a la población sobre la necesidad de medidas preventivas para reducir los casos y, finalmente, erradicar algunos de ellos.
\end{abstract}

Palabras clave: Brasil. Enfermedades desatendidas. Epidemiología. Medidas preventiva. País subdesarrollado.

\title{
INTRODUÇÃO
}

As zoonoses são patologias de grande interesse em saúde pública e que se manifestam principalmente em países tropicais e subtropicais (AGUDELO-SUAREZ, 2012), como é o caso do Brasil e do continente africano. Estão visceralmente ligadas a baixo desenvolvimento socioeconômico e, consequentemente, despertam pouco ou nenhum interesse dos laboratórios estrangeiros na produção de vacinas e drogas terapêuticas.

Essas enfermidades são transmitidas ao homem por meio de animais ou desses para o homem. O termo é de origem grega, onde zoo significa animal e ose, doença. Caracterizam-se por serem afecções causadas por organismos representados por vírus, bactérias, fungos, parasitos e rickettsias, denominados de patógenos e que podem se alojar em todos os órgãos e/ou sistemas, permitindo que se classifiquem essas patologias em digestivas, cutâneas, sistêmicas e respiratórias, havendo ainda outras cujos agentes têm localização mais rara. Os animais que alojam esses patógenos são conhecidos como reservatórios naturais e exercem papel importante no ciclo da doença, pois algumas enfermidades que hoje são transmitidas diretamente de pessoa para pessoa, tiveram origem em animais. Como exemplo é possível 
citar os vírus do sarampo e da rubéola, que teriam sido originados de bovinos (VASCONCELLOS, 2013; OMS, 2018).

Atualmente, a maioria das doenças infecciosas emergentes são zoonóticas e a fauna silvestre constitui um grande reservatório, sendo, entretanto, muitas vezes, desconhecido ao homem (ZANELLA, 2016). São considerados fatores determinantes para a emergência de doenças zoonóticas o aumento da população humana e outros fenômenos globais, como: as alterações ambientais, incluindo as mudanças climáticas e a perda da biodiversidade, comércio e viagens, mudanças no habitat terrestre, poluição e expansão da produção animal (CHOMEL; BELOTTO; MESLIN, 2007).

Entre as zoonoses mais prevalentes no Brasil pode-se destacar a febre maculosa, influenza aviária, larva migrans cutânea, leishmaniose, leptospirose, raiva, toxoplasmose, tuberculose, esquistossomose, doença de Chagas, brucelose, malária, febre amarela e dengue. Muitas dessas zoonoses são endêmicas, como a malária e a esquistossomose e outras têm manifestação epidêmica, como é o caso da dengue. Já a doença de Chagas, antes muito comum principalmente no interior das regiões sudeste e sul, está em declínio em função das mudanças no tipo de construção civil adotado nessas cidades. As habitações antigas eram de palmito ou madeira, permitindo que seu vetor, percevejos hematófagos chamados de "barbeiros" se escondessem nas frestas, saindo a noite para se alimentar de sangue humano e transmitindo o patógeno. Outro exemplo de zoonose em declínio é a cisticercose, que pode causar cegueira ou manifestações neurológicas importantes, e que tem a presença de porcos contaminados com as larvas da Taenia solium em seu ciclo. A contaminação ocorre quando carne de porco sem inspeção adequada e com os cisticercos é ingerida crua ou malpassada, desenvolvendo a doença. Nas capitais e cidades maiores a fiscalização sobre a venda de carne suína tem reduzido significativamente sua manifestação. Necessário destacar que em cidades menores o hábito de abater suínos em abatedouros não fiscalizados ou clandestinos ainda é grande, contribuindo para que essa doença ainda seja comum nessas populações (OMS, 2018).

Com a introdução no Brasil do hábito do consumo de peixe cru em nossa alimentação, através de sushi, sashimi e ceviche, aumentou consideravelmente o aparecimento de zoonoses transmitidas pelo pescado em nosso país. Essas patologias são de difícil diagnóstico pelo fato de os laboratórios de análises clínicas e a classe médica não estarem ainda familiarizados com essas zoonoses, explicando, assim, a ausência de artigos sobre esse tema (PAVANELLI et al., 2015).

Após essas observações e motivado pela importância das zoonoses para a população brasileira, os autores resolveram efetuar levantamento cienciométrico exaustivo visando contribuir para o delineamento do panorama de publicações científicas sobre o as zoonoses que ocorrem no Brasil. Isso 
irá permitir implementação de novos estudos que possam abordar aspectos relevantes ou negligenciados em relação as zoonoses.

\section{PERCURSO METODOLÓGICO}

Este trabalho é classificado quanto ao tipo como sendo descritivo-explicativo e de natureza quantitativa. A ferramenta utilizada para o trabalho é o levantamento bibliográfico por meio de banco de dados. A metodologia para planejamento, coleta e análise de dados para este estudo será baseada na abordagem cienciométrica (MARTINS, 2016).

$\mathrm{Na}$ busca, foram utilizadas as chaves de busca ou strings, que possibilitaram identificar as obras já publicadas que apresentem correlação com o tema abordado. Como estratégia, na busca inicial foi descrita as delimitações de itens-chaves como "zoonose humana" associada ao "Brasil" ou "clima tropical”, bem como as palavras em Inglês "zoonosis human "and "Brazil”.

Deste modo, artigos que relacionam as zoonoses ao Brasil e abrange doenças de interesse para a saúde humana, foram pesquisados em bases de dados nacionais e internacionais, e classificadas segundo a data da publicação, nome do periódico eletrônico e sua qualificação do Webqualis.

As bases de dados que foram consultadas a princípio são United States Nacional Library of Medicine (PubMed) disponível em http://www.ncbi.nlm.nih.gov/pubmed, Scientific Eletronic Library Online (Scielo), disponível em http://www.scielo.br/, Literatura Latino-Americana e do Caribe em Ciências da Saúde (Lilacs), disponível em http://lilacs.bvsalud.org/ e Centro Latino-Americano e do Caribe de Informação em Ciências da Saúde, disponível no website http://bvsalud.org/. Foi utilizado o banco de dados epidemiológicos do Instituto Brasileiro de Geografia e Pesquisa-IBGE. A busca ficou pré delimitada às bases citadas, sujeita à vieses de pesquisa devido ao acréscimo de novas fontes bibliográficas.

Foram excluídos do trabalho os títulos com duplicidades, os trabalhos que após análise de títulos e resumos, não relacionem uma zoonose de interesse para a saúde humana à uma condição epidemiológica prevalente brasileira.

Para a classificação segundo o local, foram consideradas as informações expressamente indicadas nos títulos e resumos sobre o país ou cidade de realização do trabalho de campo ou coleta de amostras. 
Nos casos excepcionais em que o título ou resumo omitiam esta informação, foi adotado o local da publicação com base no primeiro autor.

\section{RESULTADOS E DISCUSSÕES}

Importante ressaltar que a quase totalidade das publicações registradas se referem aos ciclos evolutivos dos patógenos e hospedeiros das zoonoses, métodos de controle de vetores, medidas profiláticas, desenvolvimento de medicamentos e aspectos clínicos, ciclos evolutivos dos patógenos e hospedeiros das zoonoses, métodos de controle de vetores, medidas profiláticas, desenvolvimento de medicamentos e aspectos clínicos. Após as buscas realizadas nas bases de dados pertinentes, encontrouse registros das seguintes zoonoses, acompanhada do número de artigos de cada uma: O número total de artigos foi de 188. Achatina fulica (2), Angiostrongilíase (3), Bertiellose (2), Borreliose (5), Brucelose (6), doença de Chagas(3), Chikungunya (2), Clostridium difficile (1), Criptosporidiose (1), Dengue (5), Difteria (2), Dirofilariose (1), Equinococose (1), Erliquiose (1), Esporotricose (21), Esquistossomose (2), Fasciolose (1), Febre Amarela (7), Giardíase (5), Hanseníase zoonótica (1), Hantavirose (5), Hepatite E (1), Leishmaniose (28), Leptospirose (8), Listeriose (2), Malária (11), Orthopoxvirus (1),Proxvirus(3), Raiva (10), Riquetsiose (5),Rotavírus humano (2),Teníase (1), Toxocaríase (12), Toxoplasmose (12), Tungíase (1), Tricuríase(1), Vírus Vaccinia (6), Zika (7) (Figura 1).

Figura 1 - Relação das zoonoses encontradas, acompanhada do número de artigos de cada uma

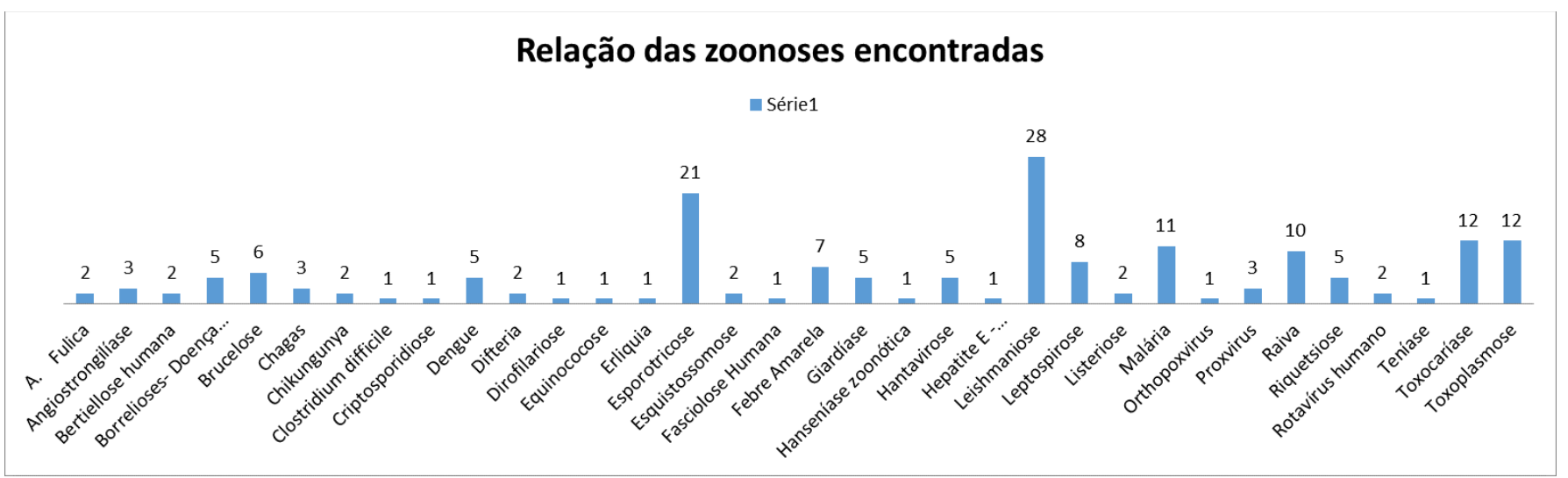

Ao se analisar as publicações distribuídas por estado, percebeu-se que os estados de Minas Gerais, com (27) registros, São Paulo com (34) e o Rio de Janeiro com (46) aparecem como aqueles com maior número de artigos publicados. 
Figura 2 - Publicações por estado da federação.

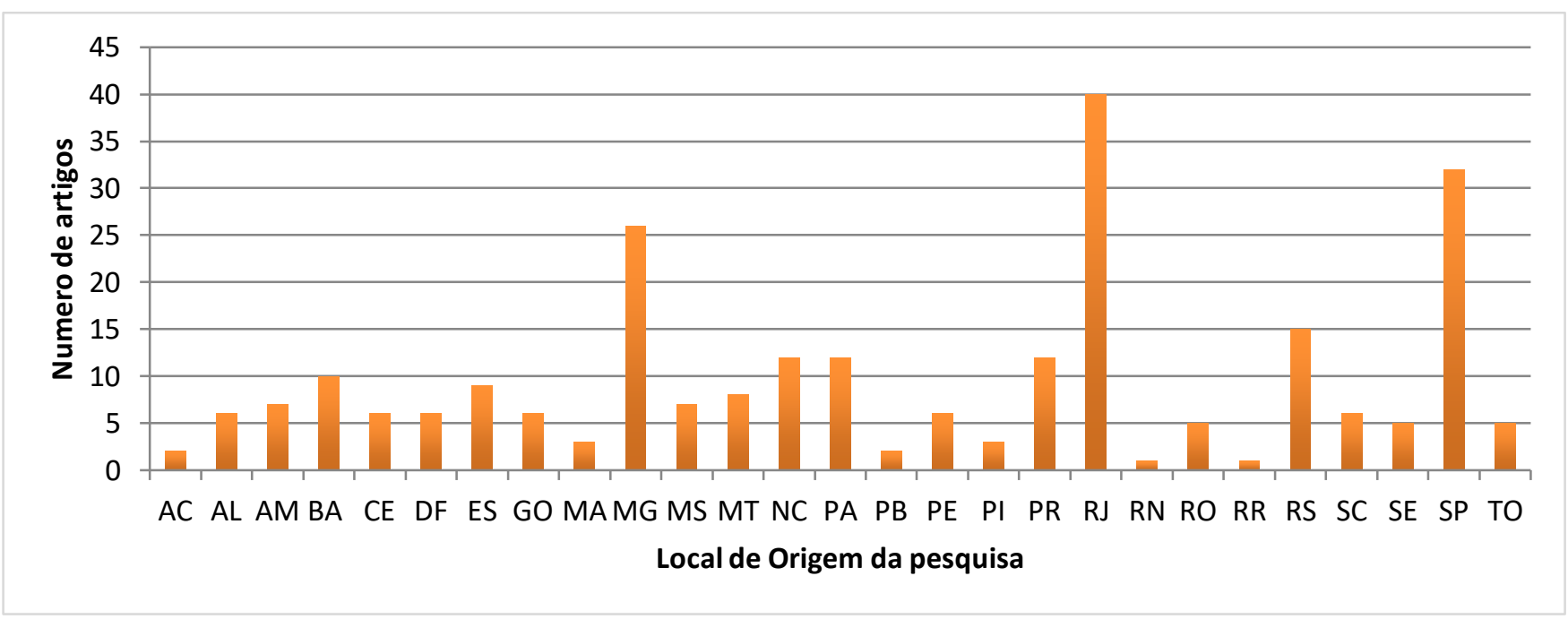

Esse resultado, coincide com as expectativas, pois são três estados que concentram o maior número de atividades de pesquisa na área.

Considerando os níveis das publicações através do Qualis - CAPES (2013-2016), verifica-se que a maioria das publicações se enquadra no nível Qualis B1, seguido do nível B2, A1 e A2. Figura 3.

Figura 3 - Distribuição do Qualis CAPES 2013-16

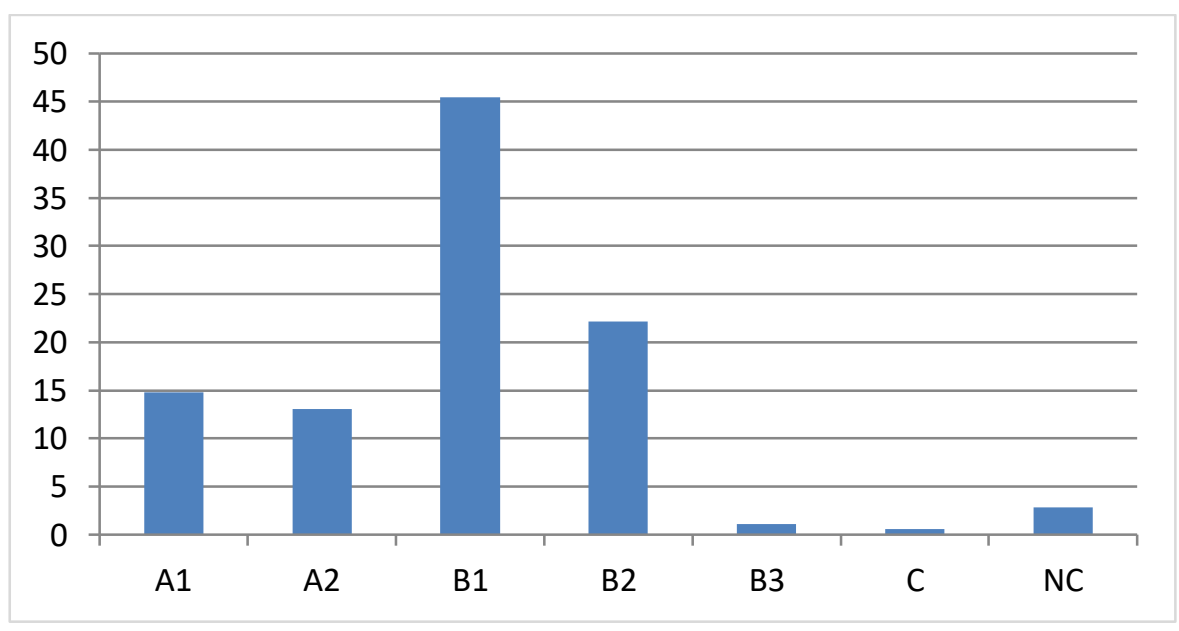


A CAPES classifica as publicações nos níveis A1, A2 e B1 como sendo do extrato superior e os demais como extrato inferior. Nesse sentido, verifica-se que a maioria das publicações são enquadradas no extrato inferior, dificultando que pesquisadores de países mais desenvolvidos tenham acesso facilitado a essas informações.

Segue-se os artigos registrados, considerando-se os anos de publicação.

Figura 4 - Distribuição dos artigos publicados por ano

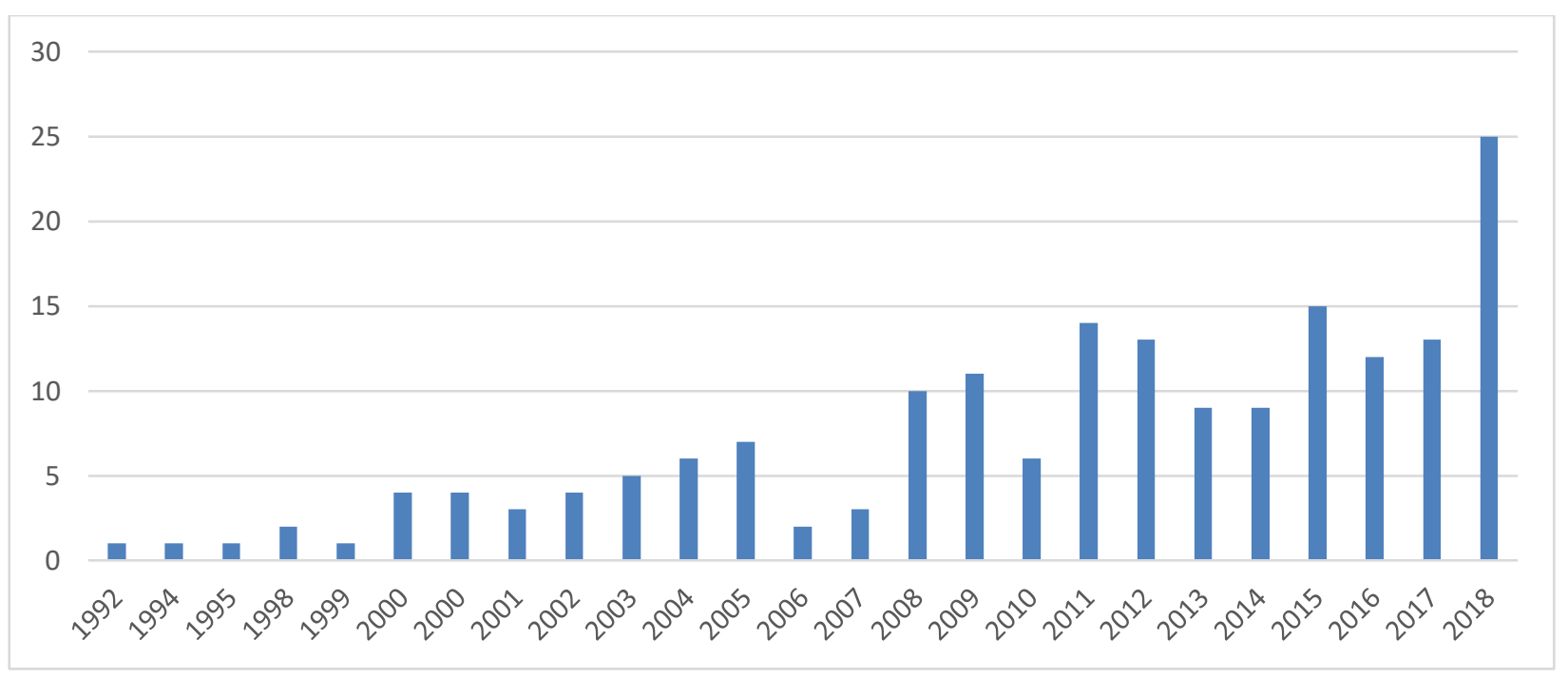

E possível observar que essas publicações oscilaram nos vários anos, não mostrando padrão claro de crescimento. Em 2013, 14, há um decréscimo, compatível com o desmanche das bolsas da CAPES. A expectativa é que esse aumento nas publicações verificados em 2018, se repitas nos anos seguintes.

\section{CONSIDERAÇÕES FINAIS}

Esses resultados mostram, entre outros aspectos, que é necessário melhorar o nível das publicações nacionais sobre as zoonoses, além de concentrar as pesquisas na prevenção, diagnóstico e tratamento dessas enfermidades. Mostram também, a necessidade em desenvolver políticas públicas com o objetivo de chamar a atenção da população sobre a necessidade de se combater os vetores das zoonoses e consequentemente reduzir o número de casos.

Esse pequeno número de registros dos casos, confirma que a quantidade de recursos investidos na área ainda é incipiente, aliado ao fato de sermos um país emergente e com grande extensão territorial. 


\section{Referências}

AGUDELO-SUAREZ, A. N. Aproximación a la complejidad de las zoonosis en Colombia. Rev. salud pública, Bogotá, v. 14, n. 2, abr. 2012. Disponível em: https://revistas.unal.edu.co/index.php/revsaludpublica/a rticle/view/35833/37846. Acesso em: 08 jul. 2019.

CHOMEL, B. B.; BELOTTO, A.; MESLIN, F. X. Wild animals, exotic pets and emerging zoonoses. Emerging Infections Diseases, n.13, v.1, p.16-11, jan. 2007.

MARTINS, M. F. M. Análise bibliométrica de artigos científicos sobre o vírus Zika. Rev Eletron Comun Inf Inov Saúde, v. 10, n. 1, 2016. Disponível em: https://www.reciis.icict.fiocruz.br/index.php/reciis/artic le/view/1096/pdf_1096. Acesso em: 08 maio 2018.

ORGANIZAÇÃO MUNDIAL DA SAÚDE - OMS. Primeiro relatório da OMS sobre doenças tropicais negligenciadas: avanços para superar o impacto global de doenças tropicais negligenciadas. Disponível em: http://bvsms.saude.gov.br/bvs/publicacoes/primeiro_rel atorio_oms_doencas_tropicais.pdf. Acesso em: 08 maio 2018.

ORGANIZAÇÃO MUNDIAL DA SAÚDE - OMS.

Zoonoses. Disponível em:
http://www.who.int/topics/zoonoses/en/. Acesso em: 08 maio 2018.
Recebido em: 20/09/2019

Aceito em: 08/11/2019

Endereço para correspondência:

Nome: Gilberto Cezar Pavanelli

Email: pavanelli@nupelia.uem.br

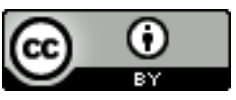

Esta obra está licenciada com uma Licença Creative Commons Atribuição 4.0 Internacional. 